\title{
NARRATIVAS DE EXPERIÊNCIAS NA NÃO-BINARIDADE: DISCUTINDO GÊNERO, IDENTIDADES E DIFERENÇAS
}

nEILTON DOS REIS

Universidade Federal de Minas Gerais

RONEY POLATO DE CASTRO

Universidade Federal de Juiz de Fora

RESUMO O artigo, baseado em uma pesquisa de mestrado em educação, tem como objetivo discutir questões relacionadas a gênero, binaridade e não-binaridade de gênero, identidades e diferenças, a partir de excertos das narrativas de três jovens que se identificam como pessoas não-binárias, construídas a partir de entrevistas-narrativas durante os anos de 2016 e 2017. Com as narrativas selecionadas, analisa-se como os sujeitos vão construindo identidades e diferenças, tendo como parâmetros os mecanismos instituídos pelas normas binárias de gênero; como os sujeitos expressam em seus corpos a identificação e a diferenciação em relação à matriz de inteligibilidade binária de gênero; e, por fim, as experiências de desconforto e violências experienciadas pelos sujeitos, que negociam seus modos de ser, agir, sentir e pensar na relação com outros.

Palavras-chave: Gênero. Não-binaridade de gênero. Identidades. Diferenças. Narrativas.

\section{ABSTRACT NARRATIVES OF EXPERIENCES IN NON-BINARITY:}

\section{DISCUSSING GENDER, IDENTITIES AND DIFFERENCES}

The article, based on a master's degree research in education, aims to discuss issues related to gender, binarity and non-binarity of gender, identities and differences, from the narratives of three young people who identify themselves as non-binary people, constructed from narrative interviews during the years 2016 and 2017. With the selected narratives, we analyze: how subjects construct identities and differences, based on parameters and mechanisms established by binary gender norms; how subjects express in their bodies the identification and differentiation in relation to the binary gender intelligibility matrix; and, finally, the experiences of discomforts and violence experienced by the subjects, who negotiate their ways of being, acting, feeling and thinking about the relationship with others. 
Keywords: Genre. Non-binarity of gender. Identities. Differences. Narratives.

\section{RESUMEN NARRATIVAS DE EXPERIENCIAS EN LA NO BINARIDAD: DISCUTIENDO GÉNERO, IDENTIDADES Y DIFERENCIAS}

El artículo, basado en una investigación de maestría en educación, tiene como objetivo discutir cuestiones relacionadas con el género, la binaridad y la no bidadidad de género, las identidades y las diferencias, a partir de extractos de las narrativas de tres jóvenes que se identifican como personas no binarias, construidas a partir de entrevistas narrativas durante los años 2016 y 2017. Con las narrativas seleccionadas, se analiza: cómo los sujetos van construyendo identidades y diferencias, teniendo como parámetros los mecanismos instituidos por las normas binarias de género; como los sujetos expresan en sus cuerpos la identificación y la diferenciación en relación a la matriz de inteligibilidad binaria de género; y, finalmente, las experiencias de incomodidades y violencias experimentadas por los sujetos, que negocian sus modos de ser, actuar, sentir y pensar en la relación con otros.

Palabras-clave: Género. No binaridad de género. Identidades. Diferencias. Narrativas.

Imagem 1: Obra da campanha "No soy tu chiste", de Daniel Arzola.

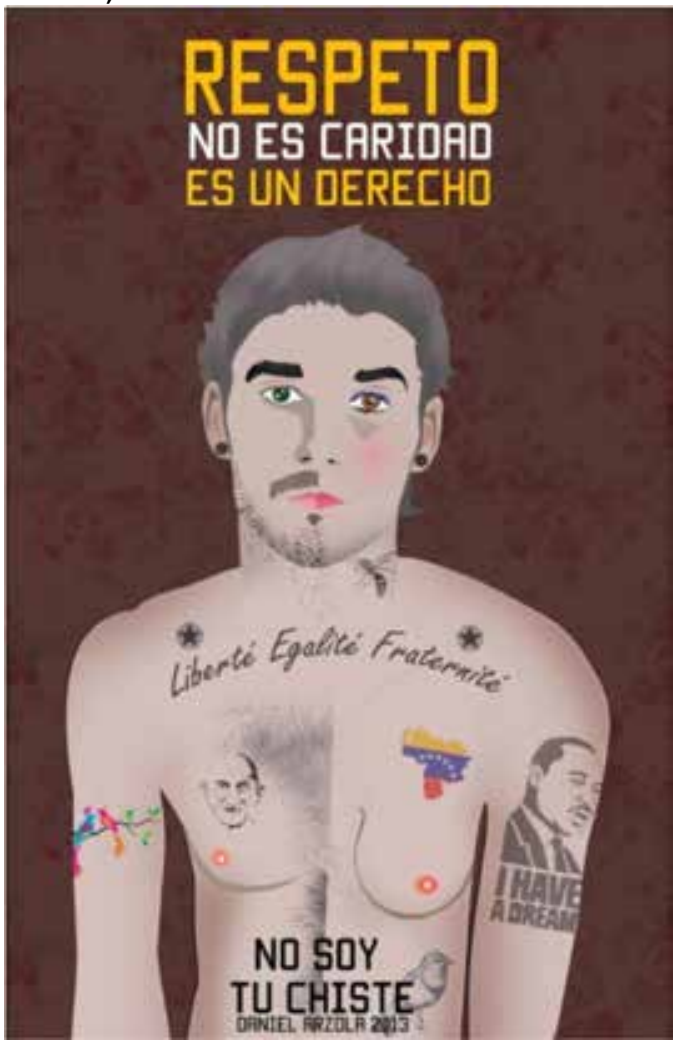

Fonte: ARZOLA, 2013.
O corpo de expressão séria.

o corpo que parece dividido.

O corpo que não quer se localizar.

O corpo no entre-lugar dos signos do binário feminino/masculino.

O corpo foi a escolha de Netuno, integrante da pesquisa que gerou este texto, como a imagem mais representativa de si dentre as produzidas por Daniel Arzola, na campanha No soy tu chiste. Uma escolha de identificação ao objeto, mas também uma analogia com sua própria trajetória dentro das construções e descobertas de gênero e sexualidade. Parece-nos uma identificação com uma composição de lutas e resistências: o lema da Revolução Francesa, o stencil de Martin Luther King, a frase que exige respeito - temática também recorrente em nossos encontros. 0 respeito que não é caridade. 0 respeito como direito, garantia de vida e 
mínimo ético (ANDRADE, 2007), para a redução de uma condição precária na vida.

Como foi dito, Netuno é um dos indivíduos que construíram uma pesquisa que gerou materiais e inquietações para a escrita deste artigo. Juntamente com Elfo e Irene - todos nomes fictícios - narraram suas experiências de identificação com a não-binaridade de gênero. Todas as narrativas produzidas, assim como todas as obras de Daniel Arzola, trazem alguns signos de desestabilização do binário através de uma tentativa de representação da diferença - daquilo que não se suporta em uma identidade, mas que foi capturado momentaneamente.

Dentro dessas tentativas de (se) dizer (n)a não-binaridade de gênero, construímos alguns relatos que irão, desse momento em diante, servir de base à discussão deste artigo. Relatos de memória, quereres e afetações. Por entre essas afetações, a questão de respeito, de desrespeito, de violência, de violação, de resistências e lutas faz saltar ao olhar. As narrativas vão, voltam, retomam, flertam e se ligam a essas questões: as formas como as existências dessas pessoas estão precarizadas pelas relações e instituições. São dimensões que vão se materializando como constitutivas dos indivíduos a cada experiência narrada, a cada situação descrita.

Ouvir os relatos e afetos nos lança a pensar em outras questões. É um ponto de partida que faz brotar novas reflexões. 0 objetivo deste texto é fazer uma discussão no enlace gênero, identidades e diferenças, partindo de narrativas que foram construídas com três pessoas durante o processo de mestrado em Educação. Essas narrativas dizem da violência que essas pessoas sofrem e são expostas, ao tensionarem o binário de gênero. Acreditamos que, para além de proporcionarem reflexões sobre a própria questão da violência de gênero, elas têm grande potencialidade para nos debruçarmos sobre o campo da identidade e da diferença.

Elfo, Irene e Netuno identificam-se com as experiências da não-binaridade de gênero, que tem se produzido, como problematizou a pesquisa, em função da diferenciação do ser homem e do ser mulher. Em outras palavras, elas buscam romper com as identidades dos gêneros que se dizem exclusivamente masculinos ou exclusivamente femininos - rompendo também com a própria logica binária do ou. Elas intentam borrar essas fronteiras e inventar suas próprias formas de se desterritorializar e (re)territorializar as relações, expressões e desejos. As entrevistas-narrativas ocorreram a partir de encontros individuais, nos anos de 2016 e 2017. As conversas giraram em torno de suas histórias de vida, foram gravadas em áudio e transcritas integralmente.

Sendo uma importante dimensão para este texto e para as pesquisas que construímos, consideremos importante sinalizar nossa concepção de narrativa. Caminhando com Corinne Squire (2014), a narrativa é uma visão ampla de "uma cadeia de signos com sentidos sociais, culturais e/ou históricos particulares" (2014, p. 273). Assim, intentamos caminhar junto a essas falas. Sendo também construtoras deste texto, não buscamos interpretar as experiências ou revelar algo que esteja por trás de cada história narrada. Ao contrário, as utilizamos para operar com os conceitos (e/ou as palavras) produzidos durante cada conversa. Escolhemos voltar o olhar a partir da perspectiva pós -estruturalista sobre essas construções narrativas e tensioná-las, fazê-las vibrar no campo do Gênero, da Sexualidade e da Educação. E em consonância com esse pensamento, Camila Junqueira Muylaert et al (2014) indicam que as narrativas produzidas são:

representações ou interpretações do mundo e, portanto, não estão abertas a comprovação e não podem ser julgadas como verdadeiras ou 
falsas, pois expressam a verdade de um ponto de vista em determinado tempo, espaço e contexto sociohistórico. $(2014$, p. 194)

Assim, as experiências são narradas já interpretadas ou representadas, e não temos acesso a elas, mas apenas a suas sombras, rápidas capturas. Da mesma forma, o próprio momento da conversa constitui-se como um disparador de experiências e que, neste texto, também é narrado (na perspectiva de que já é interpretado ou representado, simples capturas), ou seja, não se trata da conversa em si, mas de como narramos os elementos que nos parecem mais potentes para este texto. É interessante pensar que as narrativas são produzidas a partir de uma relação. Toda palavra, todo conceito emerge de um jogo. E é esse jogo que poderá ser o disparador da experiência, para todas as pessoas que construíram a pesquisa. Estamos territorializados por parcialidades, afetos, sentimentos. Cada narrativa sobre a qual nos demoramos produz efeitos tanto para quem conta, quanto para quem ouve - podem provocar (des)subjetivações em todas as pessoas envolvidas no diálogo.

Pensando num sentido de constituição e responsabilidade, é importante sinalizar que o caminho metodológico foi realizado seguindo os critérios de cuidado e ética. Todas as pessoas assinaram um Termo de Consentimento, através do qual assumiram, de maneira voluntária, livre e esclarecida, os riscos e benefícios da pesquisa e se declaravam cientes dos objetivos e interesses da metodologia em questão. E assinaram ainda um termo adicional que permitia a exposição de seus nomes sociais, uma vez que, no meio do processo, entendemos a importância dessa dimensão em suas vidas. No mesmo sentido, foram garantidas que seriam respeitadas durante todo o processo de construção, bem como suas ideias.

Após esta introdução, o artigo será organizado em três seções: a primeira, lançando um olhar às questões específicas das transgressões ao binário de gênero; em seguida, passamos ao atravessamento de identidades e diferenças e à problematização das identidades na relação com as normas; em terceiro, investimos na discussão sobre violências e a reivindicação do respeito nos atravessamentos de identidades e diferenças. Por último, finalizamos o artigo com considerações finais acerca do que foi discutido ao longo do texto.

\section{"Você tá vestida assim porque você quer ter um pinto?" - gênero em (não)binários e dominações}

Pesquisador: $E$ você acha que as pessoas te cobram muito esse se enquadrar, de se vestir ou se portar dentro de algo masculino ou feminino?

Netuno: Se as pessoas cobram... sim. Sempre com dúvida. As pessoas chegam e "ah, você tá vestida assim porque você quer ter um pinto?". Pergunta assim, na cara dura mesmo se quero ter um pinto, coisa assim. Já ouvi essa pergunta tipo diversas vezes, diversas pessoas. Nunca aqui no meio da universidade, que eu acho que as pessoas têm bom senso. Mas eu acho que as pessoas têm bastante curiosidade por não saber mesmo. Os preconceitos que sofri e sofro, é por eu estar vestida de uma forma fora que meu corpo pede, por exemplo eu tenho corpo feminino e tô vestida de forma masculina. As pessoas, quando eu chego num lugar, já olham pro meu peito, pra ver se eu tenho peito, pra ver se eu sou uma menina mesmo. As pessoas ficam querendo saber.

Teve um dia que eu tava no ônibus e eu tava com uma camiseta mais apertada. Aí tinha um cara que ele me olhou uma vez, aí tá. Aí ele olhou de novo pra ver mesmo o que eu era. $\mathrm{E}$ ele ficou tipo: olhando pro meu peito e olhando pra minha cara, olhando pro meu peito e olhando pra minha cara, e eu fiquei muito desconfortável com aquilo.

É aquela coisa né, o corpo feminino tem que acompanhar acessórios femininos e vestimentas femininas, e o masculino a mesma coisa: 
acessórios masculinos e vestimentas masculinas. E quando você mistura os dois num corpo só, as pessoas ficam mais confusas ainda. Elas ficam tipo "ah mas você não é sapatão? Mas você não é...". Não sei, confunde as pessoas. Aí tem gente que enxerga na maldade, tem gente que enxerga com olhar de ignorância mesmo, de não saber o que é, mas não de maldade. Curiosidade. Às vezes não sabe fazer a pergunta da forma correta, mas a gente sabe quando é na maldade e quando não é. (Netuno - 2016)

“Ah, você tá vestida assim porque quer ter um pinto?" Por que está assim? Por que esse corpo? Por que esse peito? Por que esse masculino? Por que esse feminino? Por que esse perguntar? Por que os porquês? Quanta vontade de saber! Quanta vontade de vigiar e enquadrar o gênero! De apertar e questionar e classificar e materializar e enquadrar e incorporar e cheirar e tocar e transar com o gênero!

"Ah, você tá vestida assim porque quer ter um pinto?" Um pinto. Um pau. Um pênis. Um falo. Qual a pergunta? "Ah, você tá vestida assim porque quer ter um pinto?" ou "você que tem uma vagina, quer dominar?" ou ainda "você quer ter o poder de um homem?" Uma marca é insistente na determinação dos lugares dos sujeitos: órgãos sexuais, pênis e vagina. Argumentando pela lógica normativa, algo que poderia ser traduzido com a frase: ter ou não ter pênis... eis a questão! Um marcador corporal que enquadra e exige, como veremos a seguir, a coerência entre o que se expressa - nos gestos, nas vestimentas, nos modos de sentar, de andar, de agir, de pensar - e o que constituiria a materialização primeira dessa expressão - o órgão sexual. Um marcador que define lugares de poder, como se o pênis concedesse aos sujeitos certas possibilidades e não outras de experienciar as relações sociais e os jogos de verdade que definem quem nós somos e quem podemos ser.
Pensar o gênero. 0 que Netuno chama de curiosidade ou maldade, diz dos saberes e poderes que engendram e mantêm viva a lógica binária. A curiosidade e a maldade surgem da constatação de um corpo que não se enquadra em certo binário de gênero. Poderíamos dizer, seguindo a narrativa de Netuno, que um corpo enquadrado na lógica binária teria um conforto, traduzido na possibilidade de não ser notado/a, de não se transformar em alvo do olhar que classifica e que institui o abjeto. E o abjeto, como nos diz Butler (2002), fala de corpos cujas vidas não são importantes. Corpos que materializam subjetividades pouco aceitáveis no espectro de uma matriz de inteligibilidade que sinaliza os limites do esquema binário. Corpos que experienciarão o desconforto de serem observados e comparados a partir dos modelos que compõem essa matriz. A experiência de Netuno nos coloca a pensar no conforto impossível na vida social. Impossivel? Mas que possíveis podemos inventar se estamos em uma lógica ocidental binária (HERMANN, 2014)? O que pode o gênero que não quer se limitar nessa lógica? O que tenta escapar da lógica da dominação?

Sinalizamos, a partir da narrativa de Netuno, que há certa incapacidade de narrar o gênero e, por conseguinte, a não-binaridade de gênero, não se colocando ou se referenciando em uma lógica binária. As situações pelas quais Netuno passa no dia a dia insistem na materialização de um esquema de pensamento que utiliza o "ou" como chave principal. $\mathrm{Ou}$ isso, ou aquilo. E ainda, geralmente, essa materialização se baseia em questões do corpo. Nesse sentido, penso com Bourdieu (1998), quando indica que:

esses esquemas [binários] de pensamento, de aplicação universal, registram como que diferenças de natureza, inscritas na objetividade, das variações e dos traços distintivos (por exemplo em matéria corporal) que eles contribuem 
para fazer existir, ao mesmo tempo que as 'naturalizam', inscrevendo-as em um sistema de diferenças, todas igualmente naturais em aparência; de modo que as previsões que elas engendram são incessantemente confirmadas pelo curso do mundo, sobretudo por todos os ciclos biológicos e cósmicos. (BOURDIEU, 1998, p. 16)

A definição de gênero como inscrições sociais e culturais por cima de uma natureza - amplamente difundida - remete a essa construção e à perpetuação dos esquemas binários. Em um momento produz-se o binário natureza/cultura, concomitante encerra-se a natureza dentro do binário macho/fêmea, restringindo as possibilidades de movimentação, de identidade e de diferença. Assim, as narrativas de Netuno (e também de Elfo e Irene, mais à frente) vão continuar operando a partir de parâmetros individuais, que são atravessados pela cultura, para falar do meio do caminho, do trânsito, da tentativa de não ser mulher/ não ser homem e das sanções sociais a que sujeitos que tentam escapar dessas restrições enfrentam. No trecho de narrativa destacado, Netuno fala do desconforto provocado por seu corpo que expressa inconformidade com o binário. Na pesquisa, e cotidianamente, ouvimos outras tantas narrativas que falam de preconceito, de discriminações, de exclusão social e de violências verbais, físicas e simbólicas.

Judith Butler (2003) vai dizer que os investimentos em vários binários instituem uma "grade de inteligibilidade cultural por meio da qual os corpos, gêneros e desejos são naturalizados" (2003, p. 23). A naturalização opera no sentido de conciliar sexo genital feminino e o ser mulher, bem como o sexo genital masculino e o ser homem; e essas duas possibilidades se complementam em um desejo heterossexual. Como narra Netuno: "É aquela coisa né, o corpo feminino tem que acompanhar acessórios femininos e vestimentas femininas, e o masculino a mesma coisa: acessórios masculinos e vestimentas masculinas". Quando os su- jeitos constituem linhas de fuga a essa noção de complementaridade, passam a confundir e embaralhar gênero e sexualidade: "Elas ficam tipo 'ah mas você não é sapatão'". Essa matriz heteronormativa será produzida e reproduzida em relações de poder. Será aprendida, como indica Bourdieu:

essa aprendizagem é ainda mais eficaz por se manter, no essencial, tácita: a moral feminina se impõe, sobretudo, através de uma disciplina incessante, relativa a todas as partes do corpo, e que se faz lembrar e se exerce continuamente através da coação quanto aos trajes ou aos penteados. Os princípios antagônicos da identidade masculina e da identidade feminina se inscrevem, assim, sob forma de maneiras permanentes de se servir do corpo, ou de manter a postura, que são como que a realização, ou meIhor, a naturalização de uma ética. (1998, p. 38)

O corpo como espaço de inscrição, de aprendizado, de obediência e dominação. A noção de aprendizado nos remete ao argumento de Michel Foucault (2002), quando afirma que não podemos entender a norma como um elemento natural (da mesma forma que não podemos entender o gênero ou o sexo nessa perspectiva): "a norma não é simplesmente um princípio, [...] é um elemento a partir do qual certo exercício do poder se acha fundado e legitimado" (FOUCAULT, 2002, p. 62). Os reforços de utilização de determinadas cores (azul para meninos, rosa para meninas), as regulações nos modos de ser e estar, os brinquedos que são dados às crianças entre outros, serão exercícios do poder (re)construtores das normas de gênero. São técnicas para a instituição do exclusivamente feminino ou exclusivamente masculino, para conformação dos corpos - do modo de cortar o cabelo ao modo de ser e estar no mundo - para que se concretize a continuidade entre sexo, gênero e, futuramente, desejo.

Judith Butler (2014) argumenta que gênero é uma norma que opera no âmbito das práticas 
sociais, porém, nem sempre de modo explícito: "quando elas [as normas] operam como o princípio normalizador da prática social, elas geralmente permanecem implícitas, dificeis de perceber e mais clara e dramaticamente discerniveis nos efeitos que produzem" (2014, p. 252). O olhar que estranha e esquadrinha o corpo de Netuno -“olhando pro meu peito e olhando pra minha cara", "pra ver se tenho peito, pra ver se eu sou uma menina mesmo" é um desses modos de expressão implícita do gênero como norma. A pergunta a Netuno: se o modo como se vestia era porque queria ter um pinto, também expressa essa naturalidade da norma, como um elemento que transforma o indivíduo em sujeito: "tornar-se sujeito de uma regulação equivale a ser assujeitado por ela, ou seja, tornar-se sujeito precisamente porque foi regulado" (BUTLER, 2014, p. 252).

A norma, segundo Butler (2014), governa inteligibilidades, de modo que determinadas práticas e ações servirão para definir "os parâmetros do que será e do que não será reconhecido como domínio do social" (2014, p. 253). Assim, ao conferir inteligibilidade ao social e normatizá-lo, os sujeitos fora da norma continuariam a ser definidos em relação a ela. "Não ser totalmente masculino ou não ser totalmente feminina é continuar sendo entendido exclusivamente em termos de uma relação a 'totalmente masculino' e 'totalmente feminina' (2014, p. 253).

Narrar algumas experiências de não-binaridade é continuar a evocar parâmetros do binário de gênero (e tais parâmetros são, em geral, de masculinidades e feminilidades hegemônicas, mantendo a perspectiva da dominação). Entretanto, como mostra Bourdieu (1998, p. 22): "a indeterminação parcial de certos objetos autoriza, de fato, interpretações antagônicas, oferecendo aos dominados uma possibilidade de resistência contra o efeito de imposição simbólica". Esse parece ser o dire- cionamento dessas narrativas com as quais trabalhamos neste artigo. Possibilidades de resistência. Re-existências de pessoas dominadas, considerando que os indivíduos que se identificam com a não-binaridade de gênero possam questionar a norma, já que estão incluídos na norma. Incluídos na norma e tratados como abjetos. Como argumenta Butler (2014, p. 253), se gênero é o mecanismo pelo qual noções de masculino e feminino são produzidas e naturalizadas, então gênero também pode ser "o aparato através do qual esses termos podem ser desconstruídos e desnaturalizados".

Incluídos na norma e, muitas vezes, reforçando-a: "os dominados aplicam categorias construídas do ponto de vista dos dominantes às relações de dominação, fazendo-as assim ser vistas como naturais" (BOURDIEU, 1998, p. 46). Um esquema de pensamento forjado pelas instâncias de dominação e que tenta impossibilitar até a imaginação para fugas. Netuno, que foi designado como mulher ao nascer, tem seios e passa pelo estranhamento de tantas pessoas quando utiliza "roupas masculinas". Netuno mesmo sinaliza "roupas masculinas" e "roupas femininas". Mas como escapar? Possuir uma corporeidade designada enquanto feminina e estar um uma lógica de dominação masculina nos permite alguns questionamentos: como se dá a subjetivação dos corpos designados como femininos? Quais atravessamentos são comuns às pessoas que foram designadas a esse gênero ao nascer? Como as experiências não-binárias podem se expressar em corpos que são cerceados, autodesconhecidos? Quais as fugas que foram acessadas para que se possa atualmente pensar o próprio corpo enquanto estrutura aberta às (des) (re)construções?

Para finalizar esta seção, gostaríamos de chamar a atenção para um atravessamento interessante que a narrativa de Netuno nos fez 
pensar. Quando diz - "os preconceitos que sofri e sofro, é por eu estar vestida de uma forma fora que meu corpo pede, por exemplo eu tenho corpo feminino e tô vestida de forma masculi$n a$ " -, destaca os incômodos que a "mistura de gêneros" pode causar. 0 masculino e o feminino juntos. É possível? Como poderia o masculino se misturar aos signos do dominado? Como se aliar a algo tão "fraco"? Questionamentos assim nos conduzem ao que Bourdieu (1998) vai chamar de "cilada": o privilégio masculino.

O privilégio masculino é também uma cilada e encontra sua contrapartida na tensão e contensão permanentes, levadas por vezes ao absurdo, que impõe a todo homem o dever de afirmar, em toda e qualquer circunstância, sua virilidade. (1998, p. 64)

A norma binária de dominação impõe suas regras: tanto para dominados, quanto para dominantes. Parece nítido que o conjunto de violências e violações que os dominantes sofrem não se comparam ao conjunto que os dominados vão enfrentar, entretanto é interessante perceber que aquilo que está designado para um gênero ou outro, na maioria das vezes, não será totalmente bem recebido, aceito sem desconforto ou facilmente aprendido: "a 'feminilidade' assim como a 'masculinidade' não são no fim das contas nada mais que categorias sociais, fluidas e provisórias apesar de sua solidez intrínseca, criadas na diagonal de uma série de discursos e de práticas" (MARTUCCELLI, 2003, p. 342).

\section{"Que tanto essa mulher me olha?" - identidades e diferenças}

Aí esses dias, eu estava dentro do ônibus também e tinha uma mulher. Ela tava me olhando. Eu pensando "que tanto essa mulher me olha?" e tal. Aí eu comecei a reparar que ela tava olhando pra ver o tamanho dos meus seios, aí eu peguei e fechei a minha blusa. Fechei a blusa. E como era larga, não dava pra ver. Aí ela chegou e falou assim pra mim: "nossa, veio um vento frio né?!". Aí eu "é, concordo, plenamente". Aí ela "nossa, sua voz é bonita". E eu "obrigado". Aí eu peguei e parei o assunto assim, fiquei na minha.

Então são situações que a gente passa que é engraçado. Mas por um lado é ruim. Porque você sabe que: "a pessoa não pede isso de mim". Por mais que você pense que faz, por mais que você tente se classificar ou tente não se classificar, vai depender dela. Se ela vai classificar. Tem gente que chega a te chamar de aberração. É ruim. Mas... Igual, tem uma pessoa que eu tava, que eu tô interessado. Mas, eu acho que penso besteira. Quando ela perceber de fato o que acontece. Eu acho que vai... sei lá. Mas aí isso só em dezembro. Então, como diz minha psicóloga "deixa que até dezembro você vai encontrando até outra coisa por aí; você conhece aquela outra lá do clube". Aí eu "não, não quero não". Tem dia que eu tô andando na rua e fico até com medo de encontrar com ela. Porque nossa, vai que essa menina começa a me perguntar: o que que tava bom, o que tava ruim. Mas, imagina se ela me vê andando, sei lá. Aí eu não sei sabe. Eu fico com medo do que ela vai pensar, do que vai passar na cabeça dela, "ah que nojo, que não sei o que....". Aí é isso. (Elfo - 2016)

"Que tanto essa mulher me olha?" E reverberando o questionamento de Elfo: que tanto essa mulher me classifica? Que tanto essa mulher me lê? Que tanto essa mulher cobra eu me enquadrar? Que tanto essa mulher quer saber quem eu sou? Que tanto essa mulher quer dizer quem eu sou? E eu sou? Kathryn Woodward (2000) defende que uma identidade é relacional. Nesse sentido, tratar de não-binaridade é (se) relacionar diretamente com a binaridade. Pensar a identidade é sinalizar que iremos construir um pertencimento identitário a partir do encontro com os outros: seja quando nos diferenciamos daquilo que encaramos como totalmente feminino e totalmente masculino, seja quando nos aproximamos de experiências que são próximas às nossas. Assim, a construção se daria tanto em uma rejeição, quanto em uma ligação. 
É no movimento de pensar o quão relacional é uma identidade que encontramos a questão mais perturbadora, quando se intenta desestabilizar o binário: a defesa de uma perspectiva que acabe em um novo engendramento. Como se deslocar de um pensamento que constrói mais e mais binários? A identidade, sendo relacional, pressupõe binários? Há possibilidades de escape?

Argumentamos que o conceito de identidade é plural e complexo. Há muitas pesquisas e diferentes perspectivas, enfoques e intenções, quando se trabalha com essa dimensão da identidade em si. Stuart Hall (2011) indica: "como ocorre com muitos outros fenômenos sociais, é impossivel oferecer afirmações conclusivas ou fazer julgamentos seguros sobre as alegações e proposições que estão sendo apresentadas" (HALL, 2011, p. 8-9). Assim, nos aliamos a Danilo Martuccelli (2003), visitando três pistas que o autor nos coloca para discutir essa dimensão dos indivíduos.

O primeiro ponto é a questão da identidade estar passando por uma crise na modernidade. Seja no aspecto social mais amplo, seja nas particularidades dos indivíduos - e entendendo que essas dimensões não estão separadas - a modernidade, toda modernidade, está condicionada pela crise. Dialogando com Michel Foucault (1999), o investimento na identidade a partir das questões que se colocam está localizado:

numa dada época, recorta na experiência um campo de saber possível, define o modo de ser dos objetos que aí aparecem, arma o olhar cotidiano de poderes teóricos e define as condições em que se pode sustentar sobre as coisas um discurso reconhecido como verdadeiro. (FOUCAULT, 1999, p. 219)

Se, em outros tempos, não era possível inventar e levar a cabo questionamentos como o que a não-binaridade de gênero coloca para a sociedade, no momento que vivemos, esses pontos específicos saltam aos olhos. Em outras palavras, quando olhamos para a identidade dentro desse momento, em meio a contextos sociais e culturais que nos permitem pensar (e nominar assim) quaisquer categorias, observamos com Danilo Martuccelli (2003) a crise que perpassa a desinstitucionalização, ou seja, “o que antes estava a cargo coletivamente das instituições e cada vez mais transmitido ao indivíduo mesmo, que desde então deve assumir, baseado na forma de trajetória pessoal, seu próprio destino" (2003, p. 292).

Está, assim, cada vez mais subjetiva a responsabilidade identitária, entretanto se continua sentindo a cobrança e a exigência de assumir identidades. É interessante destacar que não são apenas as pessoas que se identificam como não-binárias que terão necessidade da identidade, mas todas as pessoas que se fixam em identidade de gênero (ser homem ou ser mulher, por exemplo). Na nossa constituição enquanto indivíduos, desde crianças, somos impelidos a pensar dentro de algo, a nos sentirmos pertencentes. Somos culturalmente cobrados: temos um nome, frequentamos escolas que nos dividem por faixa etária e gênero, somos perguntados/as de nossas identidades sexuais, nos classificamos em raça e etnia etc.

E talvez seja exatamente essa a motivação que atravessa o indivíduo que diz da não-binaridade de gênero. Ainda que construa o desejo de romper com a estruturação binária, não necessariamente irá construir o desejo de romper com a necessidade de identificar-se. 0 sentimento de pertencimento, ainda que imponha quaisquer fronteiras, talvez seja mais confortável que se colocar sempre à margem das questões identitárias: "Por mais que você pense que faz, por mais que você tente se classificar ou tente não se classificar, vai depender dela. Se ela vai classificar. Tem gente que chega a te chamar de aberração. É ruim". 
Essa reflexão já nos lança ao segundo ponto de Martuccelli (2003): “a identidade é o que permite, em um único movimento, sublinhar a singularidade de um indivíduo e, junto, nos colocar dentro de uma certa cultura ou de uma certa sociedade, parecida a algumas outras" (2003, p. 289). Nesse sentido, a construção identitária parece se dar em um jogo de aproximação e distanciamento de padrões que estão estabelecidos e, então, vão se fortalecendo ou transformando. Aquilo que é engraçado e aquilo que é ruim, como narra Elfo. Parâmetros que vão produzindo identidades e significando discursos, práticas, símbolos etc.

Tratando especificamente das questões de gênero (e da não-binaridade), estando engendrados em um sistema de classificação, simbólico e de linguagem binária, será justamente por conhecermos bem esse sistema binário que poderemos perceber qualquer legibilidade em uma possível identidade nãobinária. Será por ter uma percepção do que é totalmente feminino ou totalmente masculino dentro do sistema que perceberemos as marcações identitárias da não-binaridade: o trânsito, a mistura, o rompimento/atravessamento das fronteiras, a fluidez. A identidade se sustentaria, desse modo, tanto na afirmação quanto na exclusão. Assim, a não-binaridade enquanto identidade será negociada com as diferenças e outras identidades dentro de um universo de pluralidade.

Se o binário de gênero é construído socialmente, a transgressão a ele não poderia ser diferente. Entendendo, como Butler (2014), que gênero se move além do binarismo naturalizado, a invenção pode ser um guardar "consigo o ato de resistir, de inventar uma nova resistência e de criar linhas de fuga que abram brechas nas territorialidades fechadas e dominadas" (SEGURADO, 2007, p. 56). Inventar uma nova nomenclatura de gênero é, assim, uma tentativa de (re)inventar-se, pensar em novas formas de se movimentar simbólica e socialmente. Como apontado por Kathryn Woodward (2000): "a construção da identidade é tanto simbólica quanto social" (2000, p.10, grifos da autora). A relação dessas duas dimensões trará conformações identitárias não apenas para as pessoas, mas também para qualquer coisa que se engendre nas políticas de certa identidade.

Apresentamos então a última pista de Martuccelli:

a identidade, seja atribuída ou assumida, positiva ou negativa, essencialista ou construtivista, só existe por uma estratégia social que a põe frente a uma alteridade. A identidade depende da diferença, não apenas por razões lógicas, mas também por razões constitutivas, posto que a vida social passa inevitavelmente pela capacidade estratégica para defini-las. (2003, p. 343)

Nesse sentido, só há possibilidade de delimitar fronteiras identitárias balizando o que está dentro a partir daquilo que deixamos de fora. Assumir qualquer identidade pode ser dizer que nenhuma das masculinidades ou feminilidades conhecidas comportam as experiências que estão em jogo. É estar marcado pelo olhar do outro, da alteridade: "'que tanto essa mulher me olha?'" Elfo, ao comentar sobre o olhar da mulher, que funciona como estratégia normativa para marcar uma identidade abjeta, narra uma constatação que dialoga com o que vimos discutindo: "por mais que você tente se classificar ou tente não se classificar, vai depender dela. Se ela vai classificar". A relação entre identidade e diferença, como nos lembra Martuccelli (2003) é constitutiva dos sujeitos. A operação de classificar, tomando certos parâmetros de inteligibilidade, é facultada a todos/as, de modo que a identidade não se trata apenas de como eu me vejo, como eu me apresento socialmente, mas de como os outros me veem e, sobretudo, como os outros estabelecem relações comigo a partir dessa classifica- 
ção. Sendo assim, podemos pensar nos efeitos na norma: vigiar, constranger, trazer desconforto, corrigir, punir, no intuito de conter a fuga, conter a tentativa de escape.

Pensamos também que a diferença pressupõe hibridismo e heterogeneidade: a diferença como aquela experiência em que não mais é possível a classificação ou a identificação, a delimitação de uma fronteira, o enquadramento, o resumo em uma unidade básica, mas que é cercada por elementos das identidades (mesmo colocando em suspensão tais elementos). É o que também Woodward (2000) defende:

As identidades são fabricadas por meio da marcação da diferença. Essa marcação da diferença ocorre tanto por meio de sistemas simbólicos de representação quanto por meio de formas de exclusão social. A identidade, pois, não é o oposto da diferença: a identidade depende da diferença. (2000, p. 39-40, grifos da autora)

Reconhecemos a importância das políticas identitárias, as quais se organizam na contraposição às formas de exclusão social baseadas em modelos identitários normativos, ou seja, identidade e diferença em relação de mútua constituição. Porém, como nos recorda Guacira Louro (2001), tais políticas visavam alcançar igualdade de direitos no interior de uma ordem social vigente, a partir da afirmação da identidade (mulher, homossexual etc.). Esse processo supunha "demarcar fronteiras e implicava numa disputa quanto às formas de representá-la" (2001, p. 543). Reconhecer-se nessa identidade era, portanto, uma questão pessoal e política. Há que se problematizar esse esquema de representação, argumentando, como propõe Louro (2001), que "ao afirmar uma dada posição-de-sujeito, supõe, necessariamente, o estabelecimento de seus contornos, seus limites, suas possibilidades e restrições" (2001, p. 544). Ou seja, os discursos que instituem as identidades também podem exercer efeitos reguladores e disciplinadores. A título de exemplo, a autora cita a situação das políticas homossexuais na década de 1970, colocadas sob questionamento na medida em que se constatava que estavam marcadas por valores brancos e de classe média, por ideais convencionais, como a monogamia, pelo privilegiamento masculino e pela marginalização de identidades bissexuais, sadomasoquistas e transexuais. 0 que se pretendeu colocar em xeque era a concepção de identidade unificadora e assimilacionista, buscando integrar os excluídos ao sistema social heteronormativo.

Deborah Britzman (1996) corrobora tais argumentos, ao discutir que o modo como as identidades são assumidas pelos sujeitos está atrelado a uma visão equivocada de que elas são dadas ou recebidas e não negociadas (social, política e historicamente). Ao analisar a constituição das identidades sexuais, Britzman (1996) argumenta que elas são tanto uma relação social no interior do eu, como uma relação social entre outros seres. Sendo assim, estaria sendo "constantemente rearranjada, desestabilizada e desfeita pelas complexidades da experiência vivida, pela cultura popular, pelo conhecimento escolar e pelas múltiplas e mutáveis histórias de marcadores sociais como gênero, raça, geração, nacionalidade, aparência física e estilo popular" (1996, p. 74). Reconhecemos que as políticas identitárias apresentam limites quando se trata de tentar abarcar algumas experiências em uma representação eleita como símbolo de luta e existência. Como indica Michel Foucault (2004): "sim, ela [a política de identidade sexual] é muito útil, mas é uma identidade que nos limita e, penso eu que temos (e devemos ter) o direito de ser livres" (2004, p. 266). Assim, a diferença em si pode nos dar ferramentas outras para refletir sobre essas questões.

Quando Netuno e Elfo narram seus incômodos e desconfortos sobre como o olhar do 
outro os coloca num lugar de abjeção, ou seja, daquele que se torna estranho e que é, portanto, motivo da atenção, por seu rompimento com certa inteligibilidade (binária) de gênero, deixam exposto um processo conflituoso e instável de construção identitária. Mais do que isso, esse encontro com o outro demarca um processo de reconhecimento do dominante como uma identidade presumida, natural, normal, estabelecendo assim os parâmetros para classificar esses corpos abjetos. A existência de Netuno e Elfo e sua tentativa de rompimento com a ordem binária podem ser interpretadas como um perigo à ordem social vigente, contaminando qualquer modelo estável de identidade. Há também o perigo que as expressões de gênero desses sujeitos encorajem outros a assumirem para si essas identidades. Com isso, produz-se uma estabilidade naturalizada, tanto para os divergentes, quanto para aqueles enquadrados no binário. Assim, queremos colocar sob suspensão as identidades como entidades fixas e homogêneas, argumentando que existiriam processos de identificação e diferenciação dos modelos exclusivamente masculino e exclusivamente feminino. A ideia, portanto, não é criar nova oposição - identidade de gênero binária e identidade de gênero não-binária, mas afirmar uma instabilidade e uma multiplicidade que constituem a relação entre os termos, já que a demarcação identitária envolve uma negação, que representaria os limites e a coerência (a diferença como a negação do outro), ao mesmo tempo a implicação do outro na constituição de si mesmo (a diferença como mútua implicação do outro em sua constituição).

Sinalizamos que não é possivel esperar total coerência em identidade/diferença dos sujeitos. Somos incoerentes e vamos nos transformando com o tempo. Nesse sentido, aquele que acha ruim certa representação, poderá assumi-la em alguma dimensão em outros tempos; bem como aquela pessoa que preza por certa identidade poderá fomentar o questionamento, se não estiver criando novas caixinhas, novas restrições à experiência. Mas, acreditando que identidade/diferença é um falso binário, visibilizamos as possiveis hierarquias presentes nesses processos que são permeados por essas duas dimensões. Assim, não seria necessário valorar em outros binários (coerente/incoerente, bom/ruim, efetivo/ ineficaz, necessário/descartável).

As narrativas que nos conduzem à organização desta escrita expressam um movimento, para o qual somos transportados, em um turvo labirinto de experimentações e experiências, entre cortes e junções. Um labirinto em que não se perdem apenas nós, mas nossas próprias relações. Onde se perderiam as definições, as limitações, as identidades e diferenças. A confusão: já passamos por aqui? 0 embaralhamento: não estaríamos voltando? O perder-se: não há saída. E queremos uma saída? Um fim? Durante todo esse movimentar-se em narrativas, gêneros, identidades e diferenças por caminhos labirínticos, algo se fez presente: relações. Somos sujeitos que se relacionam, que narram, que se montam, que inventam. E então retomamos a discussão anunciada no início deste artigo: a dimensão do respeito. Como o respeito atravessa essas identidades e relações?

\section{"As pessoas já olham e ficam te encarando, te julgando mentalmente" - da diferença às violências}

Pesquisador: $\mathrm{E}$ as pessoas te olham estranho e te abordam, tipo na rua?

Irene: A maioria foi na rua e foram casos mais pesados assim. Eu tô sempre em desconforto. Talvez seja depressão pela ansiedade. Mas, os meus maiores desconfortos que me jogaram 
em crise mesmo foram casos de abuso verbal e de agressão. Teve duas vezes que me agrediram aqui na cidade. A primeira foi no carnaval quando eu tava ficando com um menino. E chutaram a gente, derrubaram a gente no chão. $\mathrm{E}$ eu fui chamar a polícia, porque, sei lá, eu achei que poderia dar alguma coisa e eles meio que se lixaram e se preocuparam mais pelo fato do menino ter se afirmado sobrinho ou filho de um traficante de um bairro aqui perto - eu acho que era Dom Bosco ou Teixeiras.

E o segundo caso foi esse ano mesmo que eu tava com umas amigas e a gente estava saindo de um bar. Agrediram a gente no meio da rua, do nada assim. Viraram e deram um soco e depois eles saíram correndo e também não pude fazer nada, porque eu também tava muito doida. E a primeira coisa que eu falei pra fazerem foi chamar a polícia, só que a polícia ia ridicularizar mais a gente ainda e não ia fazer nada. E aí eu percebi que nesse mundo a gente tá sozinha, pela gente mesma, com as pessoas que a gente confia. E a gente não pode contar com nada que venha do Estado, porque o Estado é moldado pra reprimir a gente, pra ridicularizar, oprimir e negar nossos direitos, tirar nossos direitos mais básicos. Na rua mesmo assim, muito cotidiano, quando eu vou com uma roupa mais diferente que se julga normal, já vejo as pessoas todas, impressionante, todas as pessoas já me olham e ficam me encarando. Pode ser um casaco, um macacão, qualquer coisinha. As pessoas já olham e ficam te encarando, te julgando mentalmente porque você está usando uma roupa que não condiz com o seu gênero de nascimento. (Irene - 2016)

"As pessoas já olham e ficam te encarando, te julgando mentalmente". As pessoas já te encaram e fazem algo. As pessoas não ficam apenas no julgamento e não param no mentalmente. As pessoas abordam e gritam, batem e abusam, deixam marcas. As pessoas também acolhem e apoiam, escutam e encontram, e deixam marcas. Durante duas pesquisas realizadas construindo narrativas acerca da nãobinaridade de gênero, algo chamou a atenção: as pessoas que relatam a diferenciação do bi- nário ser mulher/ser homem sempre narram, junto, um processo marcado por fortes violências em suas relações e seus corpos. Em outras palavras, compreendemos que há construção de sentidos, identidades e diferenças, quando se passa por essas ações violentas. E "nesse mundo a gente tá sozinha, pela gente mesma, com as pessoas que a gente confia", outras relações, que não as de violências também podem produzir: sentidos, identidades e diferenças. Acolhimento, violência, agressão, confiança, encontro entre tantas outras práticas de interação, permeiam essas narrativas.

Danilo Martuccelli (2003) explora as relações sociais, na perspectiva do respeito, focando em três regimes: a hierarquia, a igualdade e a diferença. Para o autor, esses grandes regimes foram se produzindo e se sucedendo um ao outro, mas perduram na sociedade. (2003, p. 208). A hierarquia, como regime que faz do indivíduo completamente dependente da realidade social; a igualdade, como forte na democracia, em especial se direcionamos nosso olhar à linguagem universal de direitos humanos; e a diferença, como uma política de "reconhecimento da pertinência política das especificidades culturais dos indivíduos e dos grupos, que se traduzem por vezes pela aceitação da ideia de um tratamento diferencial dos membros dessas coletividades" (2003, p. 213).

Como "o respeito está em função dos diferentes regimes de interação, porém através de obrigações que se traduzem por tensões específicas" (MARTUCCELLI, 2003, p. 214) e para dar prosseguimento a esse artigo, direcionamos 0 foco à questão do regime de diferenças e seus possíveis, no que tange ao respeito, em três pontos.

O primeiro é que "o regime da diferença torna muito mais dificil nossa comunicação com os demais, porque os avanços no respeito declinam de uma maneira visceralmente individual" (MARTUCCELLI, 2003, p. 251). Nesse sen- 
tido, percebemos certo grau de ilegibilidade na diferença, a imprecisão, o território simbólico extremamente individual (e, assim, pouco legivel em uma interação qualquer) para dizer de uma experiência, resultando na criação de atritos. Ainda que possam ser evocados signos e símbolos de identidades, nem sempre é utilizada a mesma perspectiva de significado e significante para dizer dela. Todos esses elementos não podem estar (des)(re)construídos.

No que tange ao gênero, nosso conceito tradicional, seu limite de construção binária, seu dimensionamento apenas em ser mulher/ ser homem, talvez possa não resistir às experiências na diferença que vêm sendo produzidas. Talvez seja potente, assim, pensar como se produz essa resistência às experiências, à expansão dos conceitos tradicionais, ao trabalho desconstrutivo. Acreditamos que pensar uma narrativa específica da não-binaridade como interação da diferença seja tensionar o limite de qualquer narrativa do binário de gênero, seja explorar os limites do mesmo, lançar todo o gênero ao estranhamento da diferença.

Interagir é se colocar à disposição de leitura. Montar-se pode ser querer ser lido de uma forma específica. Estar incoerente com o padrão da linha de montagem é estar ilegivel. $E$, quando há impossibilidade da leitura realizada a partir da uma chave de classificação clássica, abre-se espaço para a invenção de outra leitura, que pode colocar o sujeito no lugar do estranho, do desconhecido. Pensar a diferença, nesse ponto, implica em fomentar a confusão. Quando os significados e significantes conhecidos já não servem mais para ler aquele corpo, aquela roupa, aquele acessório, aquele cabelo etc., as consequências da ilegibilidade se materializam (seja em violência, seja em curiosidade). Os simbolos e significados podem até ser conhecidos (como o uso de um batom ou uma blusa larga), mas a conjugação deles é que torna também o corpo estranho
- como uma palavra formada por letras conhecidas, mas que não se encaixa no idioma como um todo: uma leitura muito parcial que possibilite uma interpretação equivocada.

Não há previsão para o desdobramento da relação que se estabelece na ilegibilidade, na diferença. A maior parte dos casos está ligada ao desconforto, a uma tensão que se expressa, em especial, na exclusão e rejeição. Assim, em um primeiro momento podemos pensar no processo de abjeção. Mas, em movimento paralelo, é também possível a produção do encantamento, do fascínio.

O segundo ponto que trazemos à discussão é que:

se, com a diferença, entramos em outra fase histórica, muito instável, é porque, no que se sucede, não pedimos apenas o respeito de uma parcela social, ou um respeito social geral, mas também a confirmação social de nossa autoestima pessoal. (MARTUCCELLI, 2003, p. 244).

Assim, ainda que se possa perpassar por movimentações ilegiveis à maioria dos outros indivíduos, a exigência é de confirmação social. Mas como legitimar algo que se move no desconhecido? Como confirmar aquilo e/ ou aquele que desacredito? Como promover discursos e práticas que vão diretamente de encontro ao que meu grupo social promove?

É então que se pode produzir agressões "sem qualquer motivação aparente", sem possibilidades de resistência, sem negociação. São relações de violência que se estabelecem e ensinam. "Eu percebi que nesse mundo a gente tá sozinha, pela gente mesma, com as pessoas que a gente confia". Em muitas interações, há negociações de prazeres, desconfortos, possibilidades de existência e resistências. Entretanto, caminho com Michel Foucault (1995) para pensar que algumas narrativas expressam algo mais que relações de poder: "uma relação de violência age sobre um corpo, sobre as coisas. Ela força, ela submete, ela quebra, 
ela destrói; ela fecha todas as possibilidades" (FOUCAULT, 1995, p. 243).

Percebemos essa relação de violência no que é narrado muitas vezes como algo que produz sentidos, que subjetiva e que diz das condições precárias: a submissão, a humilhação, o encerrar de possibilidades combativas àquela agressão. Se numa relação de poder poderíamos nos debruçar a pensar em formas de resistir, nessa relação de violência "não pode contar com nada".

Por fim, sinalizamos para um último ponto em Martuccelli (2003), a questão do reconhecimento:

A experiência da negociação de si é, para dizer a verdade, uma tensão fundadora, em troca, o fim buscado; ou seja, o reconhecimento se mostra sempre frágil. Reconhecido, o indivíduo é atrapalhado por seu próprio vácuo. É que o respeito exigido deve, em um único movimento, fazer-nos parecidos e diferentes, e por certo é dificil, porém não impossível, ganhar ao mesmo tempo, nos dois lados. (2003, p. 250)

Acompanhando o autor, acreditamos ser importante sinalizar que o reconhecimento da diferença não quer dizer representação do diferente. Assim, a questão não significa categorizar ou quando fazer o movimento de territorialização dentro de um espectro de identidades. $O$ diferente pode ser considerado uma nova identidade, ainda que difira do padrão hegemônico ou aceitável socialmente. Ele ocupa um território, tem lugar nas hierarquias, está incluso nas políticas identitárias (seja enquanto detentor do direito seja enquanto marginalizado).

Uma política que agregue o diferente, apesar de interessante em alguns casos, seria uma política da diversidade. Assim, arriscamos pensar que dentro do diverso teremos o idêntico e o diferente, o normal e o anormal, o aceitável e o rejeitável - teremos identidades binárias. Entretanto, não teremos a diferença em si. 0 diferente opõe-se ao idêntico. A diferença irá tensionar os padrões que definem a identidade.

$\mathrm{Na}$ mesma perspectiva, relacionamos à diferença o adiamento de sentidos. E assim, quando reconhecido, se instaura o vácuo, de modo que a questão principal é ter sempre sentidos adiados, inacabados, em trânsito. Sua definição interrompida, negada. Indicamos que pensar a não-binaridade de gênero nessa posição nos expande à possibilidade de rompimentos com os jogos de identidades (sejam essencialistas ou não), com as políticas determinantes que vêm sendo promulgadas acerca dos gêneros e das sexualidades. Michel Foucault (2004) nos traz que os sujeitos estão engendrados em uma situação estratégica de luta em relação a esses jogos de identidade e que:

não podemos nos colocar fora da situação, em nenhum lugar estamos livres de toda relação de poder. Eu não quis dizer que somos sempre presos, pelo contrário, que somos sempre livres. Enfim, em poucas palavras, há sempre a possibilidade de mudar as coisas. (FOUCAULT, 2004, p. 268).

A diferença nos traz essa possibilidade de transitar nos signos, em outras palavras, nos lança à produção de novas possibilidades de interação. E, como indica Martuccelli (2003), isso é um possivel: ganhar dos dois lados a partir da promoção do respeito.

\section{Considerações finais}

Escrever, falar, pensar e experienciar não-binaridade de gênero, a partir das narrativas das relações que se produzem, nos parece sinalizar que "as práticas discursivas são também práticas sociais organizadas e constituídas em relações de desigualdade, de poder e de controle" (LARROSA, 1994, p. 67). A organização se materializará em regulações, em negociações 
de si, em implicações práticas, enunciações e rupturas. 0 encontro dos corpos e das vidas, as formas diferenciadas de exercer poder, as resistências: tudo entrará na disputa.

Algo atravessa as três narrativas apresentadas: o "olhar" do outro. Olhares que vigiam, que investigam, que buscam classificar a partir de parâmetros de inteligibilidade de gênero que remetem ao binário exclusivamente masculino/exclusivamente feminino. Olhares que constituem corpos abjetos, ao enquadrá-los, aparentemente, fora da norma, embora sempre em relação a ela. Olhares que constituem identidades, forjadas com o outro, com aquilo que passamos a pensar sobre nós mesmos/ as a partir do modo como o outro me define. Olhares que violentam, incomodam, machucam. Deixam rastros da inadequação. Olhares atentos e constantes, que funcionam como um dos tantos elementos de construção desses processos de identificação e diferenciação que se traduzem na não-binaridade de gênero.

Os sujeitos constituem-se nesse relacionar-se e também isso permite mesmo a construção de uma narrativa de si, de uma narrativa de gênero. Os casos narrados neste artigo não soam exclusivos das experiências da nãobinaridade, mas de qualquer construção de identidade e diferença. As práticas desviantes da matriz binária de normas de gênero, desde "ficar com um menino" até utilizar "uma roupa mais diferente que se julga normal" estão sendo cobradas em relações de violência, deixando na existência de Elfo, Irene e Netuno a sensação de estar "sempre em desconforto": violência física, moral, psicológica e emocional que educa, constrói.

Voltamos a encarar a obra de Daniel Arzola, que abre este artigo, para refletir a quais precariedades os corpos que intentam transgredir o binário são expostos. Diz de corpos marcados, simbolizados, corpos que misturam e fazem uma composição para expressar não uma dualidade, mas um híbrido. Com e sem seios, com e sem barba e pelos, com e sem maquiagem: a aposta no "e", não no "ou". A composição que vai construindo um sentido de existência para sujeitos que ousam driblar as normas, sem abandoná-las por completo, referenciando-se nelas para elaborar outras expressões. Com a obra de Arzola, encaramos as narrativas de Elfo, Irene e Netuno, na tentativa de visibilizar estratégias de re-existências inventadas por essas pessoas para a manutenção da vida, o que nos faz também encarar este texto como próximo a uma ação política de criação de novos possíveis e de superação das violações.

\section{Referências}

ANDRADE, Marcelo. Educação e tolerância: articulações éticas e pedagógicas possiveis. In: REUNIÃo ANUAL DA ANPED, 30., 2007, Caxambú, MG. Anais eletrônicos... Rio de Janeiro: ANPED, 2007. Disponível em: <http://30reuniao.anped.org.br/trabalhos/ GT17-3672--Int.pdf>. Acesso em: 17 out. 2018.

ARZOLA, Daniel. No soy tu chiste. 2013. Disponivel em: <http://nosoytuchiste.tumblr.com/>. Acesso em: 20 jun. 2018.

BOURDIEU, Pierre. A dominação masculina. Rio de Janeiro: Bertrand Brasil, 1998.

BRITZMAN, Deborah P. O que é esta coisa chamada amor - identidade homossexual, educação e currículo. Educação \& Realidade, Porto Alegre, v. 1, n. 21, p. 71-96, 1996.

BUTLER, Judith. Como os corpos se tornam matéria. Entrevista a Baukje Prins e Irene C. Meijer. Estudos Feministas, Florianópolis, v. 10, n. 1, p. 155-167, jan. 2002.

Problemas de gênero: feminismo e subversão da identidade. Rio de Janeiro: Editora Record, 2003.

Regulações de gênero. Cadernos Pagu, Campinas, n. 42, p. 249-274, jan./jun. 2014. 
FOUCAULT, Michel. A arqueologia do saber. Tradução de Luiz Felipe Baeta Neves. 4. ed. Rio de Janeiro: Forense Universitária, 1995.

As palavras e as coisas. Tradução de Salma Tannus Muchail. 8. ed. São Paulo: Martins Fontes, 1999.

Ditos e Escritos I: Problematização do sujeito: psicologia, psiquiatria e psicanálise. 2. ed. Rio de Janeiro: Forense Universitária, 2002.

. Michel Foucault, uma entrevista: sexo, poder e a política da identidade. Verve, São Paulo, n. 5, p. 260-277, 2004. Disponível em: <https://revistas.pucsp.br/index.php/verve/article/view/4995/3537>. Acesso em: 18 jun. 2018.

HALL, Stuart. Identidades culturais na pós-modernidade. Tradução de Tomaz Tadeu da Silva e Guacira Lopes Louro. Rio de Janeiro: DP\&A, 2011.

HERMANN, Nadja. A questão do outro e o diálogo. Revista Brasileira de Educação, São Paulo, v. 19, n. 57, p. 477-493, abr./jun. 2014. Disponível em: <http:// www.scielo.br/pdf/rbedu/v19n57/v19n57a11.pdf>. Acesso em: 10 abr. 2018.

LARROSA, Jorge. Tecnologias do eu e educação. In: SILVA, Tomaz Tadeu. 0 sujeito da educação: estudos foucaultianos. Petrópolis, RJ: Vozes, 1994. p. 35-86.

LOURO, Guacira Lopes. Teoria queer - uma política pós-identitária para a educação. Estudos Feministas, Florianópolis, v. 9, n. 2, p. 541-553, 2001. Dispo- nível em: <http://www.scielo.br/pdf/ref/v9n2/8639. pdf>. Acesso em: 10 fev. 2019.

MARTUCCELLI, Danilo. Grammaires l'Individu. Paris: Gallimard, 2003.

MUYLAERT, Camila Junqueira; SARUBBI JÚNIOR, Vicente; GALLO, Paulo Rogério; ROLI NETO, Modesto Leite; REIS, Alberto Olavo. Entrevistas narrativas: um importante recurso em pesquisa qualitativa. Revista da Escola de Enfermagem da USP, v. 48, n. 2, p. 184-189, 2014. Disponível em: <http://www.revistas. usp.br/reeusp/article/view/103125/101472>. Acesso em: 10 abr. 2018.

SEGURADO, Rosemary. Por uma estética da reexistência na relação entre arte e política. In: CHAIA, Miguel. (Org.). Arte e política. Rio de Janeiro: Azougue Editorial, 2007. p. 41-58.

SQUIRE, Corinne. O que é narrativa? Civitas - Revista de Ciências Sociais, v. 14, n. 2, p. 272-284, 2014. Disponivel em: <http://revistaseletronicas.pucrs. br/ojs/index.php/civitas/article/view/17148/11473>. Acesso em: 10 abr. 2018.

WOODWARD, Kathryn. Identidade e diferença: uma introdução teórica e conceitual. In: SILVA, Tomaz Tadeu da. Identidade e diferença: a perspectiva dos estudos culturais. Petrópolis, RJ: Vozes, 2000. p. 7-72.

Neilton dos Reis é doutorando em Educação pela Universidade Federal de Minas Gerais (UFMG). Grupo de pesquisa: Grupelho (Grupo de Estudos e Ações em Filosofia e Educação).

e-mail: neilton.dreis@gmail.com

Endereço: Rua Violeta, 361. Bairro Esplanada. Belo Horizonte, Minas Gerais. CEP: 30280-230. Telefone: (32) 98453-2378

Roney Polato de Castro é Doutor em Educação pela Universidade Federal de Juiz de Fora (UFJF). Professor da Faculdade de Educação e do Programa de Pós-Graduação em Educação da Universidade Federal de Juiz de Fora. Grupo de pesquisa: GESED (Grupo de Estudos e Pesquisas em Gênero, Sexualidade, Educação e Diversidade). e-mail: roneypolato@ gmail.com

Endereço: Rua José Lourenço Kelmer, s/n. Campus Universitário. Bairro São Pedro. Juiz de Fora, Minas Gerais. CEP: $36036-$ 900. Telefone: (32) 98888-4520 